\title{
Stereotactic body radiation therapy in early-stage NSCLC: historical review, contemporary evidence and future implications
}

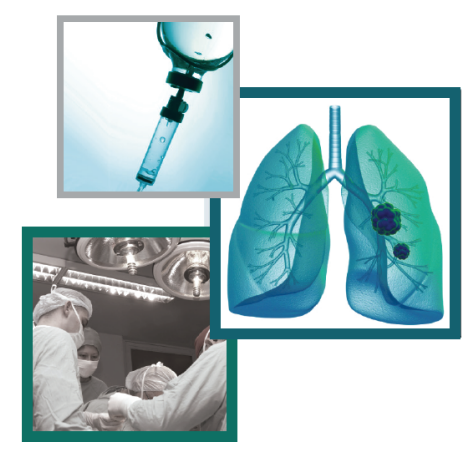

\author{
Stephen Abel ${ }^{1}$, Shaakir Hasan ${ }^{1}$, Zachary D Horne ${ }^{1}$, Athanasios Colonias ${ }^{1}$ \& Rodney \\ E Wegner*,1 \\ ${ }^{1}$ Allegheny Health Network Cancer Institute, Division of Radiation Oncology, Pittsburgh, PA, 15212, USA \\ *Author for correspondence: Tel.: +1 412359 3400; Fax: +1 412359 3171; Rodney.Wegner@ahn.org
}

Practice points

- Current standard-of-care for early-stage, nonoperative NSCLC is stereotactic body radiation therapy (SBRT).

- SBRT is a noninvasive treatment involving the precise delivery of ablative dose radiation.

- Compared with fractionated radiation, SBRT achieves superior local control and survival.

- Prospective trials comparing surgical resection versus SBRT are currently accruing.

- Lung cancer screening and the obesity epidemic may increase the incidence of inoperable cases.

Clinical use of stereotactic body radiation therapy (SBRT) has increased dramatically over the last 2 decades and is the current standard-of-care in cases of inoperable early stage non-small-cell lung cancer. While surgical resection remains the standard-of-care for operable patients, several ongoing clinical trials are investigating the role of SBRT in these operative candidates as well. Taking into consideration the expanding role and utility of SBRT, this paper will: review the historical basis of SBRT; examine landmark trials establishing the framework for the current body of evidence; discuss areas of active and future research; and identify epidemiological trends that are likely to further increase the use of SBRT.

First draft submitted: 18 October 2018; Accepted for publication: 22 January 2018; Published online: 27 February 2019

Keywords: non-small-cell lung cancer $\bullet$ stereotactic ablative radiotherapy $\bullet$ stereotactic body radiation therapy $\bullet$ stereotactic radiation

Lung cancer is a commonly diagnosed malignancy and a major cause of oncologic morbidity and mortality. In 2018, lung cancer was estimated to account for $13 \%$ of newly diagnosed malignancies, as well as $25 \%$ of cancer-related deaths in the USA [1]. Of the approximately 234,000 annual cases of lung cancer diagnosed in the USA, the vast majority (80-85\%) are of the non-small-cell lung cancer (NSCLC) variant. NSCLC is a discrete entity from smallcell lung carcinoma (SCLC) and includes the histological subtypes of adenocarcinoma, adenosquamous carcinoma, squamous cell carcinoma, large cell carcinoma and sarcomatoid carcinoma [2]. Although lung cancer historically has a poor prognosis, early-stage NSCLC (ES-NSCLC) generally has more favorable outcomes, particularly in patients amendable to surgical resection [3].

\section{Current standard of care in ES-NSCLC: surgical resection}

Surgical resection (segmentectomy or lobectomy/pneumonectomy depending on location, clinical factors and extent of disease) with mediastinal lymph node dissection represents a potentially curative treatment that is the current standard of care for patients with operable ES-NSCLC [3-5]. Survival is particularly favorable in patients with small or less invasive tumors ( $\mathrm{T} 1 \mathrm{a}-\mathrm{c}$ ), in which 5-year survival typically ranges from 80 to $90 \%$ [6]. The success of surgical resection in ES-NSCLC highlights the importance of early detection of disease in improving survival and the critical nature of identifying which patients are eligible for surgery. An adequate pretreatment workup is essential and begins with global assessment of functional status with history and physical examination, basic laboratory

Future Medicine 

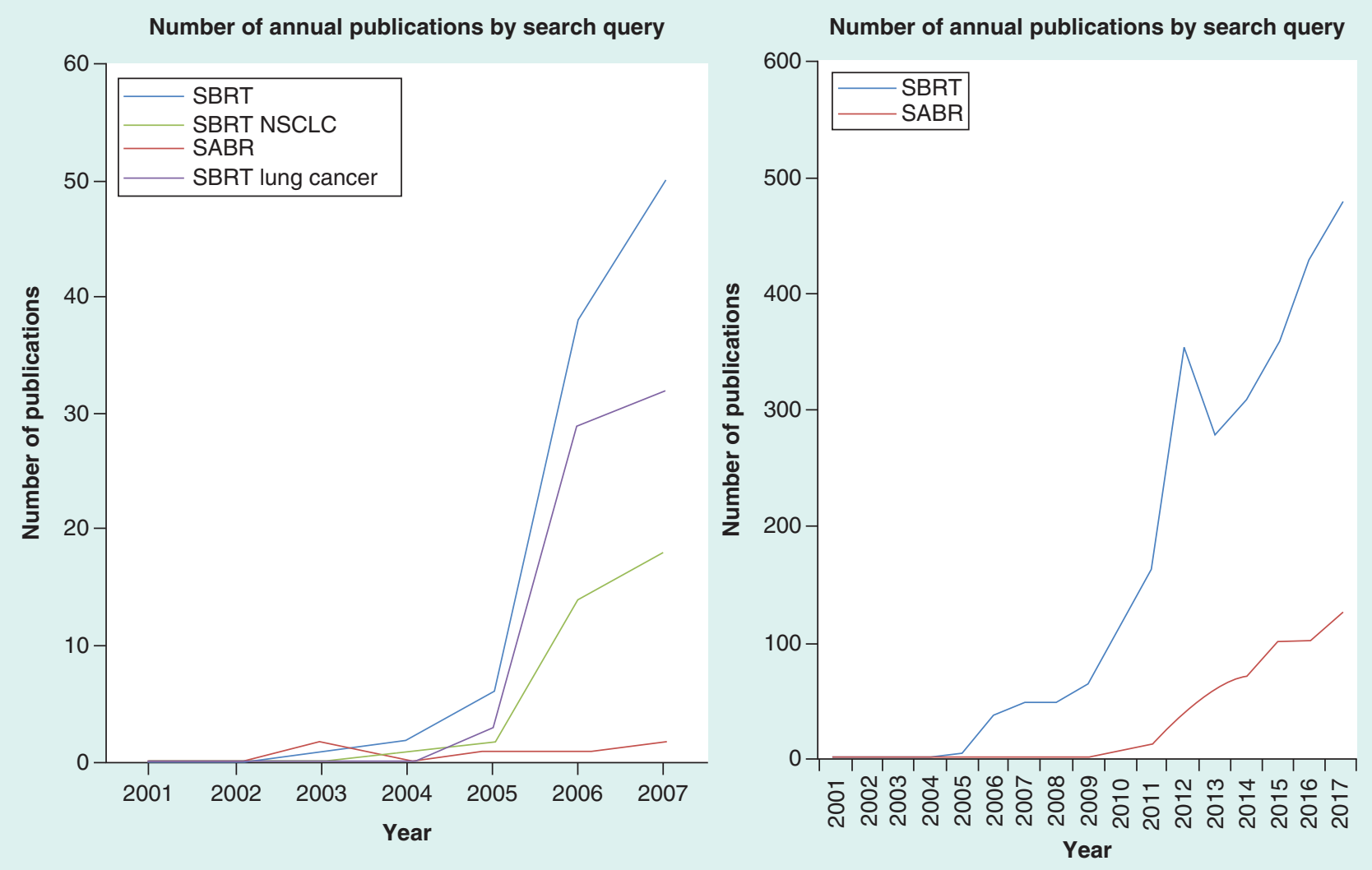

Figure 1. National Library of Medicine's PubMed publications by year based upon search query.

NSCLC: Non-small-cell lung cancer; SABR: Stereotactic ablative radiotherapy; SBRT: Stereotactic body radiation therapy.

studies and recent pulmonary function tests. In addition, noninvasive staging modalities such as the appropriate structural and functional imaging studies are obtained and, if tolerated by the patient, invasive diagnostic strategies such as endobronchial and/or mediastinal evaluation [2]. Unfortunately, many patients diagnosed with lung cancer are either frail or have comorbid cardiopulmonary disease as a result of aging and/or tobacco abuse. In a subset of these patients, the degree of frailty or severity of cardiopulmonary comorbidities precludes surgery, theoretically reducing the patient's chance of curative therapy.

\section{Historical approach to medically inoperable ES-NSCLC}

Historically, the majority of the patients, who elected observation, died from cancer despite having severe cardiopulmonary comorbidities, thus emphasizing the need for oncologic treatment $[7,8]$. These nonsurgical patients, either deemed 'medically inoperable' or refusing surgical resection, were treated with conventionally fractionated radiation therapy (CFRT) with or without concurrent chemotherapy [9-11]. Alone, CFRT was usually delivered to a total dose of 60-70 Gy in 1.8-2.0 Gy fractions. With the aid of modern 3D conformal techniques, radiation dose escalation was investigated and found to improve survival when not used concurrently with chemotherapy [11-13]. A review by Sibley et al. [12], as well as, a meta-analysis by Ramroth et al. [11], corroborated the suggestion of improved outcomes with escalation of biologically effective dose (BED). Yet, survival and local control remained far inferior to that of surgery, and general consensus was the nominal benefit of CFRT did not adequately address the therapeutic need in these nonsurgical patients [14]. In search of alternative treatment approaches and drawing on the principles of BED escalation, clinicians in Sweden and Japan began to explore hypofractionated treatment schedules [15,16]. Described as stereotactic body radiation therapy (SBRT) and/or stereotactic ablative therapy (SABR), these hypofractionated regimens showed promising results, leading to increased use globally (Figure 1) [17-24]. 


\section{Origins of SBRT}

The origins of SBRT can be traced to the successes of intracranial stereotactic radiosurgery (SRS) first conceptualized in the 1950s by Swedish neurosurgeon, Lars Leksell [25]. Leksell's first prototype design was introduced clinically in 1967 , a construct with multiple, nonopposed cobalt-60 sources arranged in a hemisphere with a surrounding collimator. Through manipulation of the collimator, output $\gamma$ rays were converged on the target with a high degree of conformality. By the 1980s, linear accelerator-based SRS platforms were developed and employed [26]. The first reports demonstrating the feasibility and safety of high-dose-per-fraction treatments in the extracranial setting were the early efforts of the Swedish and Japanese $[15,16]$. Building on the efforts of the Swedish and Japanese, a German group began to investigate the role of stereotactic radiation therapy in the setting of inoperable lung and liver tumors [27]. In light of these encouraging international results, Phase I studies were soon to follow in North America [28].

\section{Principles \& technical challenges of extracranial stereotactic radiotherapy}

SBRT is a noninvasive treatment involving the precise delivery of ablative doses of ionizing radiation in one or a 'few' fractions to extracranial sites of disease [29,30]. Regarding fractionation, the American Society of Therapeutic Radiation Oncology has a slightly more restrictive definition for SBRT (i.e., 1-5 fractions), whereas in Europe, SBRT encompasses 1-8 fractions $[29,30]$. As opposed to intracranial targets, the treatment of extracranial disease presents the challenge of target motion. This challenge is made more difficult since immobilization with a rigid frame as often utilized with intracranial SRS is not feasible given the necessary physiologic movement of the thorax. Devices such as body contour molds are utilized; however, these do not achieve the same degree of immobilization as seen with intracranial SRS. To account for limitations with immobilization, sophisticated image guidance is employed for daily target visualization and tracking during breathing-related motion. Techniques such as respiratory gating and $4 \mathrm{D}$ computed tomography have been developed to manage the issue of respiratory-related tumor motion. With appropriate image guidance, advantages of SBRT over CFRT include: higher dose-per-fraction treatments with a resultant increase in the $\mathrm{BED}$, tight target margins with sharper dose gradient leading to reduced dose to normal tissue, and shorter treatment duration minimizing patient inconvenience and allowing for initiation/resumption of systemic therapy more quickly. Since the entire treatment dose is delivered over the course of $1-5$ fractions, accuracy is of utmost importance. Errors can easily be magnified in comparison with CFRT, as an inaccuracy is more likely to allow tumor progression and/or contribute excessive toxicity to normal adjacent tissue.

\section{Early clinical evidence in medically inoperable ES-NSCLC}

In 2003, Timmerman et al., from Indiana University, was the first North American group to report results on the safety of extracranial stereotactic radiation treatment in 37 patients [28]. Treatment was delivered to a cumulative dose of 60 Gy in three fractions (without accounting for tissue heterogeneity) and found to have acceptable tolerance with only two patients developing Grade 3 acute toxicity. Phase II trials were soon to follow in North America as the Radiation Therapy Oncology Group (RTOG) enrolled patients from 2004 to 2006 [31]. Patients diagnosed with medically inoperable ES-NSCLC having peripheral tumors $<5 \mathrm{~cm}$ were included and treated to a prescription dose of $54 \mathrm{~Gy}$ in three fractions (with tissue heterogeneity correction). The results of this RTOG study (RTOG 0236) were reported in 2010 and showed excellent local control (97\%) with 3-year survival of 56\%. With local control exceeding 90-95\%, the results of this prospective study corroborated findings of several retrospective series and previous Phase I trials, suggesting a significant local control benefit with SBRT compared with that of CFRT [20-24,32]. Table 1 provides a summary of selected prospective studies.

\section{Toxicity \& adverse effects (clinically \& radiographically)}

With BED in the realm of $100-150 \mathrm{~Gy}_{10}$, significant toxicity may occur if appropriate quality assurance measures are not followed. Toxicities can present acutely ( $<1$ month from treatment) or as a late complication. Respecting normal tissue dose constraints and accurate target delineation during treatment planning and delivery is essential, particularly in patients with minimal lung reserve. Overall, treatment is well tolerated, with the majority of patients experiencing minimal to no adverse effects or decline in pulmonary function. Patients may experience treatmentrelated fatigue; however, this is usually mild and self-limiting [34]. With the exception of fatigue, adverse treatment effects and toxicity are typically related to the location of the tumor (peripheral vs central) and its proximity to adjacent organs at risk. 
Table 1. Summary of selected prospective studies assessing stereotactic body radiation therapy in NSCLC.

\begin{tabular}{|c|c|c|c|c|c|c|c|}
\hline $\begin{array}{l}\text { Study/ } \\
\text { Investigator(s) } \\
\text { [Ref.] }\end{array}$ & Publication year & $\begin{array}{l}\text { Number of } \\
\text { patients }\end{array}$ & $\begin{array}{l}\text { Radiation } \\
\text { dose/fractionation } \\
\text { (Gy) }\end{array}$ & BED $_{10}$ (Gy) & Local control (\%) & $\begin{array}{l}\text { Overall survival } \\
\text { (\%) }\end{array}$ & Toxicity ( $\geq$ Grade 3 ) \\
\hline $\begin{array}{l}\text { Kyoto University, } \\
\text { Japan/Nagata [17] }\end{array}$ & 2005 & 45 & $48 / 4$ & 105.6 & $98 \%$ & $\begin{array}{l}\text { Stage IA at: } \\
1 \text { year: } 92 \% \\
3 \text { year: } 83 \% \\
\text { Stage IB at: } \\
1 \text { year: } 82 \% \\
3 \text { year: } 72 \%\end{array}$ & None \\
\hline $\begin{array}{l}\text { Nordic } \\
\text { Group/Baumann \& } \\
\text { Nyman [29] }\end{array}$ & 2009 & 57 & $66 / 3$ & 211.2 & $92 \%$ & 3 year: $60 \%$ & $30 \%(n=17)$ \\
\hline $\begin{array}{l}\text { RTOG } \\
\text { 0236/Timmerman [31] }\end{array}$ & 2010 & 55 & $54 / 3$ & 151.2 & $93 \%$ & 5 year: $40 \%$ & $27 \%(n=15)$ \\
\hline $\begin{array}{l}\text { RTOG } \\
\text { 0915/Videtic [34] }\end{array}$ & 2013 & 84 & $\begin{array}{l}34 / 1(n=39) \\
48 / 4(n=45)\end{array}$ & $\begin{array}{l}149.6 \\
105.6\end{array}$ & $\begin{array}{l}97 \% \\
98 \%\end{array}$ & $\begin{array}{l}2 \text { year: } 61.3 \% \\
2 \text { year: } 77.7 \%\end{array}$ & $\begin{array}{l}10 \%(n=4) \\
13 \%(n=6)\end{array}$ \\
\hline $\begin{array}{l}\text { EORTC- } \\
\text { LungTech/Adebahr } 35\end{array}$ & $\begin{array}{l}2015 \\
35]\end{array}$ & 39 & $60 / 8$ & 105 & Not yet reported & Not yet reported & Not yet reported \\
\hline $\begin{array}{l}\text { SPACE/Nyman \& } \\
\text { Hallqvist [36] }\end{array}$ & 2016 & 49 & $66 / 3$ & 211.2 & $86 \%$ & $\begin{array}{l}1 \text { year: } 81 \% \\
3 \text { year: } 54 \%\end{array}$ & $14 \%(n=7)$ \\
\hline
\end{tabular}

BED: Biologically effective dose; RTOG: Radiation Therapy Oncology Group.

\section{Peripheral lesions}

By definition, peripheral lesions are located $>2 \mathrm{~cm}$ from the primary bronchi or trachea. Previous prospective studies have reported Grade 3+ toxicities of $10-20 \%$ in patient's receiving SBRT to peripheral lung lesions [37,38]. However, a number of retrospective and prospective studies have suggested that the rate of toxicity is much lower, with most reporting Grade 3+ toxicities of $<5 \%$ [39-42]. Peripheral tumors are often located further from the proximal airways and closer to the chest wall. As a result, a larger volume of chest wall receives a greater dose, thus raising the probability of local toxicity including chest wall pain, rib fractures and occasionally radiodermatitis. Retrospective analyses suggest that the risk of $\geq$ Grade 2 chest wall, skin and rib toxicity are low, but not insignificant (2-3\%) [43-46]. Both the max skin dose and volume of chest wall receiving 30 Gy have shown value in predicting toxicity $[45,47]$. Similarly, apical lung tumors have been associated with increased incidence of radiation induced brachial plexopathy. However, brachial plexopathy is more commonly due to tumor progression as opposed to radiation induced [48,49]. In addition to tumor related factors, patient related factors such as obesity and osteoporosis have also been associated with increased skin/chest wall toxicity and rib toxicity [46,50].

Radiation-induced pneumonitis is the most frequent acute pulmonary toxicity [30]. Clinically symptomatic pneumonitis develops in less than $10 \%$ of patients with most patients having asymptomatic Grade 1 pneumonitis [5153]. Predictors of $\geq$ Grade 2 pneumonits include mean lung dose of greater than $4 \mathrm{~Gy}$ and the volume of lung receiving $\geq 20$ Gy (lung V20) exceeding 4\% [54]. Pretreatment pulmonary function tests have not been shown to predict for pneumonitis [55]. The vast majority of patients develop late pulmonary toxicity characterized by asymptomatic localized pulmonary fibrosis in the high-dose treatment field [56]. Radiographic changes secondary to localized radiation induced fibrosis can lead to inaccurate radiologic interpretation. Incorrectly interpreting posttreatment changes as pneumonia can have downstream consequences including unnecessary exposure to antibiotics, needless hospitalizations and patient inconvenience. As a result, clinicians should inform patients of these effects in an effort to circumvent potential future incorrect diagnoses.

\section{Central lesions}

Located in close proximity to the mediastinal and primary tracheobronchial structures, central tumors have a degree of risk and toxicity profile that differs from peripheral lesions. In a prospective Phase II study conducted at 
Indiana University, patients with ES-NSCLC were treated to $60 \mathrm{~Gy}$ in three fractions (without dose heterogeneity correction) using SBRT [38]. Treatment of the central tumors were shown to increase patient's risk of Grade 3+ toxicity by 11-fold when compared with peripheral tumors and was a predictive factor associated with severe toxicity. These findings brought to light the challenges of safely treating centrally located tumors and established a proverbial 'no fly zone' [38]. Historically, the 'no fly zone' was defined as presence of tumor within $2 \mathrm{~cm}$ of the proximal bronchial tree, which encompassed the distal $2 \mathrm{~cm}$ of the trachea, carina, main bronchi and named major lobar bronchi [38]. As a result of safety concerns, patients with tumors present in this region were excluded from the seminal North American cooperative group trial, RTOG 0236 [31]. Since that time, multiple institutions have demonstrated the safety of SBRT in treating centrally located tumors through a combination of improved image guidance, better immobilization techniques and adjustment of dose-fractionation parameters [57,58]. Improved safety was observed with dose per fraction reductions in the range of $\mathrm{BED}_{10} 80-120 \mathrm{~Gy}$; however, this was at the expense of increasing local failure rates when de-escalated below a $\mathrm{BED}_{10}$ of $100 \mathrm{~Gy}$ [35,59]. While the optimal dose-fractionation scheme in centrally located tumors has yet to be definitively established, a safe but efficacious (i.e., $\mathrm{BED}_{10} \geq 100 \mathrm{~Gy}$ ) 'risk-adapted' regimen, in which $60 \mathrm{~Gy}$ delivered over eight fractions was first described by Dutch investigators in 2011 [23]. This regimen demonstrated both excellent 3-year local control rates (>90\%) and safety, as only $3 \%$ of patient experienced toxicity of Grade 3 or greater. These findings have led to the initiation of Phase I/II studies conducted by the RTOG (RTOG 0813) and EORTC (LungTech), which will attempt to clarify the interrelationships of dose-fractionation with safety and efficacy [33]. Recently, further characterization of central tumors has been suggested, in which tumors with direct abutment or invasion of the proximal bronchial tree, are subclassified as ultracentral [35]. Given the degree of anatomic centrality, these tumors are felt to increase the risk of treatment-related toxicity and merit further subclassification. With improvements in imaging techniques and refinement of motion management strategies, the definition of centrally located tumors will likely continue to be restricted.

\section{Comparison of SBRT versus CFRT}

As evidence supporting the role of SBRT continued to accumulate, three prospective studies were initiated to directly compare outcomes in patients treated with SBRT with CFRT. The first randomized Phase II trial was undertaken in Scandinavia from 2007 to 2011 [59]. A total of 102 patients with medically inoperable ES-NSCLC were randomly assigned to receive either SBRT ( $\mathrm{n}=49$; 66 Gy in three fractions) or CFRT $(\mathrm{n}=52 ; 70$ Gy in 35 fractions). The SBRT arm included more patients with T2 tumors compared with the CFRT arm. Although no difference in progression free or overall survival (OS) was observed, a trend toward improved disease control was observed in the SBRT group. Furthermore, quality of life and toxicity were improved with SBRT as lower rates of patient-reported dyspnea, chest pain, cough and esophagitis were observed in the SBRT arm. The results of a second prospective investigation were reported in 2017 by the Trans-Tasman Radiation Oncology Group and Australasian Lung Cancer Trials Group (NCT01014130). Patients with peripheral medically inoperable ESNSCLC were randomly assigned to receive SBRT ( $\mathrm{n}=66 ; 54 \mathrm{~Gy} / 3$ fractions or $48 \mathrm{~Gy} / 4$ fractions) or CFRT $(\mathrm{n}=35 ; 66 \mathrm{~Gy} / 33$ fractions or $50 \mathrm{~Gy} / 20$ fractions) with the primary objective of time to local failure. Patients in the SBRT arm were reported to have superior freedom from local failure (HR: 0.29; $p=0.002$ ) and improved OS (HR: $0.51 ; \mathrm{p}=0.020$ ) compared with patients receiving CFRT. A third prospective investigation was initiated in Canada in 2014 [36]. Sponsored by the Ontario Clinical Oncology Group (OCOG), this multicenter Phase III investigation is ongoing and intends to enroll 320 patients with medically inoperable ES-NSCLC to SBRT versus CFRT in a 2:1 ratio. The estimated date of study completion is 2021 , with a primary objective of local control at 5 years.

\section{Comparison of SBRT versus surgery}

The excellent local control rates $(>90 \%)$ consistently observed in both retrospective and prospective series in patients with medically inoperable ES-NSCLC treated with SBRT, in conjunction with population-based studies and propensity-matched analyses suggesting comparable OS with that of surgery, led to the initiation of several prospective Phase III investigations that attempted to directly compare outcomes of SBRT with surgery in medically operable patient's with ES-NSCLC (ROSEL, STARS, ACOSOG Z4099). Of note, many physicians were reluctant to enroll patients within the SBRT arm, as treatment with SBRT leaves patients subject to both in-lobe recurrences, as well as, in-lobe secondary primary lung cancers; complications that would otherwise not occur with lobectomy. As a result of physician and/or patient hesitancy to enroll, all three randomized trials comparing surgery with SBRT 
for ES-NSCLC (STARS [NCT00840749], ROSEL [NCT00687986] and ACOSOG Z4099 [NCT01336894]) were forced to close early due to poor accrual numbers. However, a pooled analysis by Chang et al. combining patients enrolled in the STARS and ROSEL studies was completed [42]. A total of 58 patients were included (SBRT: $\mathrm{n}=31$ and surgery $\mathrm{n}=27$ ) with a median follow-up of 35 months. Pooled estimated OS at 1 and 3 years was 100 and $95 \%$ in the SBRT group and 88 and $79 \%$ in the surgical group; a statistically significant difference $(\mathrm{p}=0.037$; HR: 0.14; 95\% CI: 0.017-1.190). No difference in local, regional or distant metastasis was observed. With regards to toxicity, $10 \%$ of patients in the SBRT arm experienced Grade 3 toxicity with no Grade 4/5 toxicities; while $44 \%$ of patients in the surgical arm experienced Grade 3/4 toxicity with one patient experiencing Grade 5 toxicity.

A meta-analysis published in 2016 by Deng et al., reviewed the results of 12 cohorts and compared outcomes of SBRT, sublobar resection and lobectomy [60]. No difference in 3-year locoregional control was observed between SBRT and resection; however, SBRT was associated with worse 3-year OS when compared with lobectomy. Interestingly, this difference in OS was not evident when comparing SBRT with sublobar resection. Considering that operative candidates generally carry less comorbidities and a higher degree of medical fitness, this perceived survival advantage may be confounded by patient selection. Patients with poorer overall health/more comorbidities (i.e., inoperable candidates) would be expected to have poorer OS compared with healthier patients (i.e., operable candidates) regardless of the local therapeutic modality employed. Additionally, more robust patients are more likely to be considered for systemic therapy in cases of disease progression, which may confound matters further. As such, the oncologic end point of OS should be interpreted with caution when comparing unbalanced populations. Although physicians may continue to be wary of in-lobe recurrences or the development of in-lobe secondary lung cancers following SBRT, retrospective data have demonstrated safe and effective use of SBRT as a salvage modality or in treatment of a new lung primary adjacent to a site previously treated with SBRT [61].

\section{Future implications}

Following a systemic literature review from 1995 to 2016, the American Society for Radiation Oncology issued a clinical guideline in 2017 regarding the use of SBRT in ES-NSCLC [62]. This guideline reinforced SBRT as the standard of care in medically inoperable patients, a viewpoint echoed by that of the American Society of Clinical Oncology in 2018 [63]. In addition, the American Society for Radiation Oncology guideline elaborated further regarding the customization of SBRT in medically inoperable patients, who have high-risk anatomic (i.e., management of centrally located tumors, tumors invading the chest wall, tumors $>5 \mathrm{~cm}$ in size) or complex clinical scenarios (i.e., salvage therapy after radiation or surgery, nonbiopsied patients, multiple primary lung cancers and patients who have underwent pneumonectomy) and the appropriateness of SBRT as an alternative to surgery for different subsets of medically operable patients (standard vs high risk of surgical-related morbidity and mortality). In regard to the latter, patients that are at greater risk of surgical morbidity/mortality or those who are unable to tolerate a lobectomy but are candidates for sublobar resection may be considered for SBRT after multidisciplinary review of the case and discussion with the patient. This subset of 'high-risk' patients often carries comorbidities that not only preclude lobectomy, but even needle biopsy. These patients have been increasingly treated with SBRT empirically (based upon PET/computed tomography [CT] findings), without establishment of a pathological diagnosis [64-66]. Overall, the results of retrospective series have been encouraging [64-66].

From an epidemiologic perspective, this subset of 'high risk' surgical candidates will conceivably increase considering the underlying healthcare landscape in the USA. First, the obesity epidemic continues to worsen, as approximately $40 \%$ of adult Americans are now considered obese [67]. Though obesity in its own right is generally not a contraindication to surgery, the multitude of comorbidities such as diabetes, cardiopulmonary disease and/or liver disease if present may preclude surgery. Second, increased screening efforts by primary care providers to detect lung cancer at an early stage will inevitably lead to an increasing number of early stage cases. Screening efforts are based upon the statement of the United States Preventative Services and Task Force in 2014 recommending annual screening for lung cancer with low-dose CT in adults age 55-80 years old who have a 30 pack-year smoking history and currently smoke or have quit within the past 15 years; a statement that has since been supported by numerous organizations including the National Comprehensive Cancer Network $[2,68]$. This recommendation carries a specifier which states that screening should be discontinued if a person develops a health problem that substantially limits life expectancy or the ability or willingness to have curative lung surgery. In an era of effective noninvasive treatment, this specifier will likely need to be modified if not eliminated.

International efforts are underway in an attempt to answer the valid question of whether SBRT and surgery are indeed at equipoise. Given the challenges of patient accrual, a Phase III feasibility study known as SABRTOOTH 
(NCT02629458) is underway in the United Kingdom to assess the recruitment rate and determine whether or not the rate is sustainable to conduct a Phase III clinical trial comparing SBRT with resection. In China, the POSTLIV trial (NCT01753414) with a primary objective of locoregional control at 2 years is ongoing and will compare lobectomy with SBRT in peripheral-based tumors. Two Phase III trials are also ongoing in the USA. The first, known as STABLE-MATES, has enrolled 102 patients and will compare 2-year disease-free and OS in high risk surgical candidates, who undergo sublobar resection versus SBRT (NCT02468024). A second trial known as VALOR (NCT02984761), involves patients within the Veteran Affairs system. The trial opened in 2017 and will compare survival outcomes and quality of life between SBRT and surgical resection. As randomized, prospective data become available, we will hopefully come closer to clarifying the role of SBRT in ES-NSCLC. In the interim, treatment decisions will continue to be rooted in the available body of evidence and from discussions with both the multidisciplinary team and, most importantly, the patient.

\section{Financial \& competing interests disclosure}

The authors have no relevant affiliations or financial involvement with any organization or entity with a financial interest in or financial conflict with the subject matter or materials discussed in the manuscript. This includes employment, consultancies, honoraria, stock ownership or options, expert testimony, grants or patents received or pending, or royalties.

No writing assistance was utilized in the production of this manuscript.

\section{Open access}

This work is licensed under the Attribution-NonCommercial-NoDerivatives 4.0 Unported License. To view a copy of this license, visit http://creativecommons.org/licenses/by-nc-nd/4.0/

\section{References}

Papers of special note have been highlighted as: $\bullet$ of interest; $\bullet \bullet$ of considerable interest

1. National Cancer Institute Surveillance, Epidemiology, and End Results Program. Cancer stat facts: lung and bronchus cancer. (2018). seer.cancer.gov/statfacts/html/lungb.html

2. National Comprehensive Cancer Network. NCCN guideline with NCCN evidence blocks - non-small cell lung cancer version 2.2019. (2019). www.nccn.org/professionals/physician_gls/recently_updated.aspx

3. Ginsberg RJ, Rubinstein LV. Randomized trial of lobectomy versus limited resection for T1 N0 non-small-cell lung cancer. Lung Cancer Study Group. Ann. Thorac. Surg. 60(3), 615-622 (1995).

4. Fan J, Wang L, Jiang G-N et al. Sublobectomy versus lobectomy for Stage I non-small-cell lung cancer, a meta-analysis of published studies. Ann. Surg. Oncol. 19(2), 661-668 (2012).

5. Altorki NK, Yip R, Hanaoka T et al. Sublobar resection is equivalent to lobectomy for clinical Stage 1A lung cancer in solid nodules. $J$. Thorac. Cardiovasc. Surg. 147(2), 754-764 (2014).

6. International Association for the Study of Lung Cancer. 8th Edition of the TNM Classification for Lung Cancer. (2018). www.necn.nhs.uk/wp-content/uploads/2015/02/6.-IASLC-8th-Edition_.pdf

7. Raz DJ, Zell JA, Ou S-HI, Gandara DR, Anton-Culver H, Jablons DM. Natural history of Stage I non-small-cell lung cancer. Chest 132(1), 193-199 (2007).

8. McGarry RC, Song G, des Rosiers P, Timmerman R. Observation-only management of early stage, medically inoperable lung cancer: poor outcome. Chest 121(4), 1155-1158 (2002).

9. Perez CA, Stanley K, Rubin P et al. A prospective randomized study of various irradiation doses and fractionation schedules in the treatment of inoperable non-oat-cell carcinoma of the lung. Preliminary report by the Radiation Therapy Oncology Group. Cancer 45(11), 2744-2753 (1980).

10. Qiao X, Tullgren O, Lax I, Sirzén F, Lewensohn R. The role of radiotherapy in treatment of Stage I non-small-cell lung cancer. Lung Cancer 41(1), 1-11 (2003).

11. Ramroth J, Cutter DJ, Darby SC et al. Dose and fractionation in radiation therapy of curative intent for non-small-cell lung cancer: meta-analysis of randomized trials. Int. J. Radiat. Oncol. Biol. Phys. 96(4), 736-747 (2016).

12. Sibley GS, Jamieson TA, Marks LB, Anscher MS, Prosnitz LR. Radiotherapy alone for medically inoperable Stage I non-small-cell lung cancer: the Duke experience. Int. J. Radiat. Oncol. Biol. Phys. 40(1), 149-154 (1998).

13. Lagerwaard FJ, Senan S, van Meerbeeck JP, Graveland WJ. Rotterdam Oncological Thoracic Study Group. Has 3-D conformal radiotherapy (3D CRT) improved the local tumour control for stage I non-small cell lung cancer? Radiother. Oncol. 63(2), 151-157 (2002).

14. Wisnivesky JP, Bonomi M, Henschke C, Iannuzzi M, McGinn T. Radiation therapy for the treatment of unresected Stage I-II non-small-cell lung cancer. Chest 128(3), 1461-1467 (2005). 
15. Blomgren H, Lax I, Näslund I, Svanström R. Stereotactic high dose fraction radiation therapy of extracranial tumors using an accelerator. Clinical experience of the first thirty-one patients. Acta Oncol. 34(6), 861-870 (1995).

- Sentinel publication assessing high dose per fraction radiation treatment in the extracranial setting.

16. Uematsu $\mathrm{M}$, Shioda $\mathrm{A}$, Tahara $\mathrm{K}$ et al. Focal, high dose, and fractionated modified stereotactic radiation therapy for lung carcinoma patients: a preliminary experience. Cancer 82(6), 1062-1070 (1998).

17. Nagata Y, Takayama K, Matsuo Y et al. Clinical outcomes of a Phase I/II study of 48 Gy of stereotactic body radiotherapy in 4 fractions for primary lung cancer using a stereotactic body frame. Int. J. Radiat. Oncol. 63(5), 1427-1431 (2005).

- Early prospective trial assessing the role of stereotactic body radiation therapy (SBRT) in cases of primary lung cancer.

18. Nyman J, Johansson K-A, Hultén U. Stereotactic hypofractionated radiotherapy for Stage I non-small-cell lung cancer - mature results for medically inoperable patients. Lung Cancer 51(1), 97-103 (2006).

19. Xia T, Li H, Sun Q et al. Promising clinical outcome of stereotactic body radiation therapy for patients with inoperable Stage I/II non-small-cell lung cancer. Int. J. Radiat. Oncol. 66(1), 117-125 (2006).

20. Zimmermann FB, Geinitz H, Schill S et al. Stereotactic hypofractionated radiotherapy in Stage I (T1-2 N0 M0) non-small-cell lung cancer (NSCLC). Acta Oncol. (Madr). 45(7), 796-801 (2006).

21. Koto M, Takai Y, Ogawa Y et al. A Phase II study on stereotactic body radiotherapy for Stage I non-small-cell lung cancer. Radiother. Oncol. 85(3), 429-434 (2007).

22. Onishi H, Shirato H, Nagata Y et al. Hypofractionated stereotactic radiotherapy (HypoFXSRT) for Stage I non-small-cell lung cancer: updated results of 257 patients in a Japanese Multi-Institutional Study. J. Thorac. Oncol. 2(7 supp 3), S94-S100 (2007).

-. Establishment of biologically effective dose threshold of $\geq 100 \mathrm{~Gy}_{10}$ in cases of NSCLC treated with SBRT.

23. Lagerwaard FJ, Haasbeek CJA, Smit EF, Slotman BJ, Senan S. Outcomes of risk-adapted fractionated stereotactic radiotherapy for Stage I non-small-cell lung cancer. Int. J. Radiat. Oncol. 70(3), 685-692 (2008).

24. Baumann P, Nyman J, Hoyer M et al. Outcome in a prospective Phase II trial of medically inoperable Stage I non-small-cell lung cancer patients treated with stereotactic body radiotherapy. J. Clin. Oncol. 27(20), 3290-3296 (2009).

25. LEKSELL L. The stereotaxic method and radiosurgery of the brain. Acta Chir. Scand. 102(4), 316-319 (1951).

26. Betti OO, Derechinsky VE. Hyperselective encephalic irradiation with linear accelerator. In: Advances in Stereotactic and Functional Neurosurgery: Acta Neurochirurgica (Volume 33). Gybels J, Hitchcock ER, Ostertag C, Rossi GF, Siegfried J, Szikla G (Eds). Springer, Vienna, Argentina, 385-390 (1984).

27. Wulf J, Hädinger U, Oppitz U, Olshausen B, Flentje M. Stereotactic radiotherapy of extracranial targets: CT-simulation and accuracy of treatment in the stereotactic body frame. Radiother. Oncol. 57(2), 225-236 (2000).

28. Timmerman R, Papiez L, McGarry R et al. Extracranial stereotactic radioablation: results of a Phase I study in medically inoperable Stage I non-small-cell lung cancer. Chest 124(5), 1946-1955 (2003).

29. Potters L, Kavanagh B, Galvin JM et al. American Society for Therapeutic Radiology and Oncology (ASTRO) and American College of Radiology (ACR) Practice Guideline for the Performance of Stereotactic Body Radiation Therapy. Int. J. Radiat. Oncol. Biol. Phys. 76(2), 326-332 (2010).

30. Haasbeek CJA, Lagerwaard FJ, Slotman BJ, Senan S. Outcomes of stereotactic ablative radiotherapy for centrally located early-stage lung cancer. J. Thorac. Oncol. 6(12), 2036-2043 (2011).

31. Timmerman R, Paulus R, Galvin J et al. Stereotactic body radiation therapy for inoperable early-stage lung cancer. JAMA 303(11), 1070-1076 (2010).

-. Landmark prospective Phase II study conducted in the USA demonstrating high rates of local control.

32. Haque W, Verma V, Polamraju P, Farach A, Butler EB, Teh BS. Stereotactic body radiation therapy versus conventionally fractionated radiation therapy for early-stage non-small-cell lung cancer. Radiother. Oncol. 129(2), 264-269 (2018).

33. Adebahr S, Collette S, Shash E et al. LungTech, an EORTC Phase II trial of stereotactic body radiotherapy for centrally located lung tumours: a clinical perspective. Br. J. Radiol. 88(1051), 20150036 (2015).

34. Videtic GMM, Reddy CA, Sorenson L. A prospective study of quality of life including fatigue and pulmonary function after stereotactic body radiotherapy for medically inoperable early-stage lung cancer. Support Care Cancer21(1), 211-218 (2013).

35. Murrell DH, Laba JM, Erickson A, Millman B, Palma DA, Louie AV. Stereotactic ablative radiotherapy for ultra-central lung tumors: prioritize target coverage or organs at risk? Radiat. Oncol. 13(1), 57 (2018).

36. Swaminath A, Wierzbicki M, Parpia S et al. Canadian Phase III randomized trial of stereotactic body radiotherapy versus conventionally hypofractionated radiotherapy for Stage I, medically inoperable non-small-cell lung cancer - Rationale and Protocol Design for the Ontario Clinical Oncology Group (OCOG)-LUSTRE trial. Clin. Lung Cancer 18(2), 250-254 (2017).

37. Fakiris AJ, McGarry RC, Yiannoutsos CT et al. Stereotactic body radiation therapy for early-stage non-small-cell lung carcinoma: four-year results of a prospective Phase II study. Int. J. Radiat. Oncol. Biol. Phys. 75(3), 677-682 (2009).

38. Timmerman R, McGarry R, Yiannoutsos C et al. Excessive toxicity when treating central tumors in a Phase II study of stereotactic body radiation therapy for medically inoperable early-stage lung cancer. J. Clin. Oncol. 24(30), 4833-4839 (2006). 
39. McCammon R, Schefter TE, Gaspar LE, Zaemisch R, Gravdahl D, Kavanagh B. Observation of a dose-control relationship for lung and liver tumors after stereotactic body radiation therapy. Int. J. Radiat. Oncol. 73(1), 112-118 (2009).

40. Haasbeek CJA, Lagerwaard FJ, Antonisse ME, Slotman BJ, Senan S. Stage I non-small-cell lung cancer in patients aged $\geq 75$ years. Cancer116(2), 406-414 (2010).

41. Videtic GMM, Stephans K, Reddy C et al. Intensity-modulated radiotherapy-based stereotactic body radiotherapy for medically inoperable early-stage lung cancer: excellent local control. Int. J. Radiat. Oncol. Biol. Phys. 77(2), 344-349 (2010).

42. Chang JY, Senan S, Paul MA et al. Stereotactic ablative radiotherapy versus lobectomy for operable Stage I non-small-cell lung cancer: a pooled analysis of two randomised trials. Lancet Oncol. 16(6), 630-637 (2015).

-. Pooled analysis of two prospective studies demonstrating equipose between SBRT and lobectomy in terms of overall survival and local control.

43. Bongers EM, Haasbeek CJA, Lagerwaard FJ, Slotman BJ, Senan S. Incidence and risk factors for chest wall toxicity after risk-adapted stereotactic radiotherapy for early-stage lung cancer. J. Thorac. Oncol. 6(12), 2052-2057 (2011).

44. Stephans KL, Djemil T, Tendulkar RD, Robinson CG, Reddy CA, Videtic GMM. Prediction of chest wall toxicity from lung stereotactic body radiotherapy (SBRT). Int. J. Radiat. Oncol. 82(2), 974-980 (2012).

45. Hoppe BS, Laser B, Kowalski AV et al. Acute skin toxicity following stereotactic body radiation therapy for Stage I non-small-cell lung cancer: who's at risk? Int. J. Radiat. Oncol. 72(5), 1283-1286 (2008).

46. Thibault I, Chiang A, Erler D et al. Predictors of chest wall toxicity after lung stereotactic ablative radiotherapy. Clin. Oncol. 28(1), 28-35 (2016).

47. Creach KM, El Naqa I, Bradley JD et al. Dosimetric predictors of chest wall pain after lung stereotactic body radiotherapy. Radiother. Oncol. 104(1), 23-27 (2012).

48. Forquer JA, Fakiris AJ, Timmerman RD et al. Brachial plexopathy from stereotactic body radiotherapy in early-stage NSCLC: dose-limiting toxicity in apical tumor sites. Radiother. Oncol. 93(3), 408-413 (2009).

49. Din S, Yamada J, Yorke E et al. Brachial plexopathy after high-dose stereotactic body radiation therapy (SBRT). Radiat. Oncol. 87(2), S518-S510 (2013).

50. Welsh J, Thomas J, Shah D et al. Obesity increases the risk of chest wall pain from thoracic stereotactic body radiation therapy. Int. J. Radiat. Oncol. 81(1), 91-96 (2011).

51. Ahmed N, Hasan S, Schumacher L, Colonias A, Wegner RE. Stereotactic body radiotherapy for central lung tumors: finding the balance between safety and efficacy in the 'no fly' zone. Thorac. Cancer 9(10), 1211-1214 (2018).

52. Cassidy RJ, Patel PR, Zhang X et al. Stereotactic body radiotherapy for early-stage non-small-cell lung cancer in patients 80 years and older: a multi-center analysis. Clin. Lung Cancer 18(5), 551-558.e6 (2017).

53. Horne ZD, Richman AH, Dohopolski MJ, Clump DA, Burton SA, Heron DE. Stereotactic body radiation therapy for isolated hilar and mediastinal non-small-cell lung cancers. Lung Cancer 115, 1-4 (2018).

54. Barriger RB, Forquer JA, Brabham JG et al. A dose-volume analysis of radiation pneumonitis in non-small cell lung cancer patients treated with stereotactic body radiation therapy. Int. J. Radiat. Oncol. 82(1), 457-462 (2012).

55. Henderson M, McGarry R, Yiannoutsos $\mathrm{C}$ et al. Baseline pulmonary function as a predictor for survival and decline in pulmonary function over time in patients undergoing stereotactic body radiotherapy for the treatment of stage I non-small-cell lung cancer. Int. J. Radiat. Oncol. Biol. Phys. 72(2), 404-409 (2008).

56. Yamashita H, Takahashi W, Haga A, Nakagawa K. Radiation pneumonitis after stereotactic radiation therapy for lung cancer. World J. Radiol. 6(9), 708-715 (2014).

57. Chang JY, Li QQ, Xu QY et al. Stereotactic ablative radiation therapy for centrally located early stage or isolated parenchymal recurrences of non-small cell lung cancer: how to fly in a "no fly zone" radiation oncology. Int. J. Radiat. Oncol. Biol. Phys. 88(5), 1120-1128 (2014).

58. Taremi M, Hope A, Dahele $\mathrm{M}$ et al. Stereotactic body radiotherapy for medically inoperable lung cancer: prospective, single-center study of 108 consecutive patients. Int. J. Radiat. Oncol. Biol. Phys. 82(2), 967-973 (2012).

59. Nyman J, Hallqvist A, Lund J-Å et al. SPACE - a randomized study of SBRT vs conventional fractionated radiotherapy in medically inoperable stage I NSCLC. Radiother. Oncol. 121(1), 1-8 (2016).

-• The first randomized Phase II trial comparing SBRT and conventional fractionated radiotherapy.

60. Deng HY, Wang YC, Ni PZ et al. Radiotherapy, lobectomy or sublobar resection? A meta-analysis of the choices for treating stage I non-small-cell lung cancer. Eur. J. Cardiothorac. Surg. 51(2), 203-210 (2017).

61. Horne ZD, Dohopolski MJ, Clump DA, Burton SA, Heron DE. Thoracic reirradiation with SBRT for residual/recurrent and new primary NSCLC within or immediately adjacent to a prior high-dose radiation field. Pract. Radiat. Oncol. 8(3), e117-e123 (2018).

62. Videtic GMM, Donington J, Giuliani M et al. Stereotactic body radiation therapy for early-stage non-small cell lung cancer: executive summary of an ASTRO evidence-based guideline. Pract. Radiat. Oncol. 7(5), 295-301 (2017). 
63. Schneider BJ, Daly ME, Kennedy EB et al. Stereotactic body radiotherapy for early-stage non-small-cell lung cancer: American Society of Clinical Oncology Endorsement of the American Society for Radiation Oncology Evidence-Based Guideline. J. Clin. Oncol. 36(7), 710-719 (2018).

64. Verstegen NE, Lagerwaard FJ, Haasbeek CJA, Slotman BJ, Senan S. Outcomes of stereotactic ablative radiotherapy following a clinical diagnosis of stage I NSCLC: comparison with a contemporaneous cohort with pathologically proven disease. Radiother. Oncol. 101(2), 250-254 (2011).

65. Wegner RE, Ahmed N, Hasan S, Schumacher LY, Van Deusen M, Colonias A. SBRT for early stage lung cancer: outcomes from biopsy-proven and empirically treated lesions. Lung Cancer Manag. 7(1), LMT01 (2018).

66. Hasan S, Colonias A, Mickus T, VanDeusen M, Wegner RE. Image-based management of empiric lung stereotactic body radiotherapy (SBRT) without biopsy: predictors from a 10-year single institution experience. Thorac. Cancer 9(6), 699-706 (2018).

67. Center for Disease Control. Prevalence of obesity among adults and youth: United States, 2015-2016. (2017). www.cdc.gov/nchs/products/databriefs/db288.htm

68. US Preventative Services Task Force. Final Recommendation Statement, Lung Cancer: screening. (2013). www.uspreventiveservicestaskforce.org/Page/Document/RecommendationStatementFinal/lung-cancer-screening 